\title{
Análise comparativa do efeito de dois protocolos de ultrassom terapêutico para regeneração de defeito ósseo crítico*
}

\section{Comparative Analysis of the Effect of Two Therapeutic Ultrasound Protocols for Regeneration of a Critical Bone Defect}

\author{
Ana Flávia Calmon Daltro ${ }^{1}$ Isabela Cerqueira Barreto ${ }^{2}$ Renata dos Santos Almeida ${ }^{1}$ \\ Iorrana Índira dos Anjos Ribeiro ${ }^{1}$ Aryon de Almeida Barbosa Junior ${ }^{3}$ Fabiana Paim Rosa ${ }^{4}$ \\ ${ }^{1}$ Laboratório de Bioengenharia Tecidual e Biomateriais (LBTB), \\ Universidade Federal da Bahia (UFBA), Salvador, BA, Brasil \\ 2 Departamento de Biofunção, Laboratório de Bioengenharia Tecidual \\ e Biomateriais (LBTB), Universidade Federal da Bahia (UFBA),

\begin{abstract}
Endereço para correspondência Ana Flávia Calmon Daltro, Instituto de Ciências da Saúde, Universidade Federal da Bahia (ICS-UFBA), Av. Reitor Miguel Calmon s/n, Vale do Canela, Salvador, Bahia 40.110-100, Brasil (e-mail: flavia_afcd@hotmail.com).
\end{abstract} Salvador, BA, Brasil

${ }^{3}$ Laboratório de Bioengenharia Tecidual e Biomateriais (LBTB),

Instituto de Patologia Geral e Cutânea (IPAC), Salvador, BA, Brasil

${ }^{4}$ Departamento de Biointeração, Laboratório de Bioengenharia Tecidual e Biomateriais (LBTB), Universidade Federal da Bahia (UFBA), Salvador, BA, Brasil

Rev Bras Ortop 2020;55(3):278-283.

\section{Resumo \\ Palavras-chave \\ - osso e ossos \\ - regeneração óssea \\ - ultrassom \\ - terapia por ultrassom}

Objetivo Comparar o efeito de dois protocolos de ultrassom terapêutico com diferentes tempos de exposição para regeneração de defeito ósseo crítico.

Métodos Foram utilizados 45 ratos, machos, distribuídos em três grupos: grupo ultrassom terapêutico 5 minutos (GUS 5); grupo ultrassom terapêutico 10 minutos (GUS 10); e grupo controle (GC). Em todos os grupos, confeccionou-se um defeito ósseo crítico, com $8,5 \mathrm{~mm}$ de diâmetro, na região da calvária. O protocolo foi iniciado no $1^{\circ}$ dia do pós-operatório, no GUS 5 e no GUS 10 , com ultrassom terapêutico na frequência de $1,0 \mathrm{MHz}$, modo pulsado, 5 vezes por semana, nos períodos de 15, 30, e 60 dias.

Resultados Dentre os grupos experimentais, houve maior neoformação de matriz osteoide no GUS 10, seguido do GUS 5 quando comparados ao GC, no qual a neoformação foi restrita à região de borda. O uso do ultrassom promoveu aumento na espessura da matriz conjuntiva, proliferação de capilares, alinhamento das fibras colágenas, redução do edema e do processo inflamatório, tendo sido mais significativo no tempo de 10 minutos.

Conclusão O ultrassom terapêutico estimulou o reparo do defeito ósseo crítico, e o maior tempo de exposição promoveu maior estímulo osteogênico.

Trabalho desenvolvido na Universidade Federal da Bahia (UFBA),

Salvador, BA, Brasil.

recebido

18 de Novembro de 2018

aceito

19 de Março de 2019
DOI https://doi.org/

$10.1055 / \mathrm{s}-0039-3402457$. ISSN 0102-3616.
Copyright $\odot 2020$ by Sociedade Brasileira License terms de Ortopedia e Traumatologia. Published by Thieme Revinter Publicações Ltda, Rio de Janeiro, Brazil 
Abstract
Keywords
- bone and bones
- bone regeneration
- ultrasound
- ultrasound therapy

Objective To compare the effect of two therapeutic ultrasound protocols, with different times of exposure, in the regeneration of critical bone defect.

Methods Forty-five male rats were distributed among 3 experimental groups: therapeutic ultrasound group 5 minutes (TUG 5); therapeutic ultrasound group 10 minutes (TUG 10); and control group (CG). In all groups, a critical bone defect of $8.5 \mathrm{~mm}$ diameter was made in the calvaria region. The protocol was initiated on the $1^{\text {st }}$ postoperative day, in TUGs 5 and 10, with therapeutic ultrasound at the frequency of 1.0 MHz, pulsed mode, 5 times a week, at periods of 15, 30, and 60 days.

Results Among the experimental groups, the highest volume of neoformation of osteoid matrix took place in the TUG 10 , followed by TUG 5 , when compared with the CG group, in which the neoformation was restricted to the border region. The use of ultrasound promoted an increase in the thickness of the conjunctive matrix, proliferation of capillaries, alignment of the collagen fibers, reduction of edema and inflammatory process, being more significant in the 10-minutes time period.

Conclusion Therapeutic ultrasound stimulated the repair of a critical bone defect, and the longer exposure time promoted greater osteogenic stimulation.

\section{Introdução}

O tecido ósseo se caracteriza por possuir propriedades de resistência e dureza decorrentes da combinação dos seus componentes orgânicos e inorgânicos. Apesar de tais propriedades, esse tecido pode sofrer lesões extensas, denominadas defeitos ósseos críticos, que comprometem a integridade estrutural e a fisiologia do reparo ósseo. ${ }^{1,2}$

Os defeitos ósseos críticos são causados por condições clínicas como, por exemplo, traumas e procedimentos cirúrgicos em que há ressecção óssea que comprometem o processo fisiológico da regeneração óssea, cujo resultado é o reparo com formação de tecido conjuntivo fibroso. ${ }^{3,4}$ Esse tecido compromete a estrutura, a função e a estética, ${ }^{5}$ pode ocasionar redução da qualidade de vida do indivíduo, impactar o desempenho das suas atividades de vida diária e laboral, com possíveis consequências psicológicas e econômicas. Nesse contexto, o fisioterapeuta, inserido na equipe multiprofissional, participa da reabilitação de indivíduos que apresentam esse quadro clínico.

Durante o processo de reabilitação, podem ser empregados recursos terapêuticos que emitem ondas mecânicas vibratórias, a fim de auxiliar o reparo e estimular a osteogênese. ${ }^{6}$ Entre esses recursos, inclui-se o ultrassom terapêutico, utilizado há anos na prática clínica fisioterapêutica, ${ }^{7}$ equipamento esse que emite ondas de alta frequência de pressão acústica que, ao interagir com os tecidos biológicos, promovem alterações micromecânicas. Essas alterações geram eventos bioquímicos capazes de acelerar a consolidação de fraturas, estimular o reparo de tecidos lesionados, como o tecido ósseo e o muscular, inibir respostas inflamatórias e participar do processo de modulação da dor. ${ }^{7-10}$

A resposta tecidual e a eficácia dessa terapia têm estreita relação com os parâmetros selecionados antes de iniciar-se o tratamento. Assim, é de fundamental importância elegeremse adequadamente a frequência, a intensidade, o modo de emissão da corrente, o tempo de aplicação e o meio acoplador indicados para cada lesão. ${ }^{7,8}$ A literatura disponibiliza uma diversidade de parâmetros, principalmente quanto ao tempo de exposição à onda ultrassônica, empregados no processo de cicatrização de fraturas ósseas.

Albertin ${ }^{11}$ confeccionou defeito ósseo de $2,0 \mathrm{~cm}$ no rádio de coelhos e estimulou a região com onda ultrassônica por 5 , 10,20 , e 40 minutos, no período de 15 dias, tendo observado que os tempos mais longos promoveram maior estímulo à consolidação óssea quando comparados com o tempo de 5 minutos. Entretanto, Pereira e outros, ${ }^{2}$ após induzir fratura na tíbia de ratos e estimular a região com ultrassom por 10 minutos, no período de 13 dias, constatou que o protocolo utilizado não promoveu diferença estatística significativa entre o grupo no qual se realizou a terapia e o grupo controle, apesar do aumento da fosfatase alcalina e do diâmetro do tecido ósseo neoformado.

Azuma et al. ${ }^{12}$ realizaram fratura no fêmur de ratos e analisaram o efeito do ultrassom por 20 minutos diários, nos períodos de 8 e 24 dias, tendo concluído que o ultrassom acelerou a cicatrização independentemente do período de tratamento, com melhora na força de torção e aumento da neoformação óssea.

Diante da diversidade de protocolos envolvidos na reabilitação de lesões ósseas, este estudo tem como objetivo comparar o efeito de dois protocolos de ultrassom terapêutico com diferentes tempos de exposição para regeneração de defeito ósseo crítico.

\section{Material e Métodos}

Este experimento foi aprovado pela Comissão de Ética no Uso de Animais, sob protocolo $n^{\circ} 101 / 2016$, e encontra-se de acordo com os preceitos da lei $\mathrm{n}^{\circ} 11.794$, de 08 de outubro de 2008, do Decreto ${ }^{\circ}$ 6.899, de 15 de julho de 2009, e com as normas editadas pelo Conselho Nacional de Controle da Experimentação Animal (CONCEA).

Os procedimentos cirúrgicos foram realizados no Biotério Central da nossa universidade, onde os animais ficaram alocados durante a realização do experimento. 
Foram utilizados 45 ratos, Rattus norvegicus, da linhagem Wistar albinus, jovens adultos, machos, com peso de 350 a 400 gramas.

A realização da técnica cirúrgica foi precedida, em todos os animais, pela anestesia geral e pela sedação com injeção intramuscular de cloridrato de cetamina $(100 \mathrm{mg} / \mathrm{kg})$ e de cloridrato de xilazina $(40 \mathrm{mg} / \mathrm{kg})$, respectivamente, a que se seguiu a tricotomia e a assepsia na região da calvária. Logo em seguida, cada animal foi posicionado em decúbito ventral para realização do procedimento cirúrgico.

A metodologia do procedimento cirúrgico foi semelhante à dos trabalhos realizados por Almeida et al., ${ }^{4}$ Miguel et al., ${ }^{13}$ Câmara-Pereira et al., ${ }^{14}$ Ribeiro et al., ${ }^{15}$ e Daltro et al. ${ }^{16}$ para confecção de defeito ósseo crítico, de 8,5 mm de diâmetro, na região da calvária ( - Figura $\mathbf{1}$ ).

Após a confecção do defeito ósseo crítico, os animais foram distribuídos em 3 grupos, com pontos biológicos de 15, 30, e 60 dias, para compor as seguintes categorias: grupo ultrassom terapêutico 5 minutos (GUS 5), com aplicação de ondas mecânicas emitidas pelo ultrassom terapêutico por 5 minutos sobre defeito ósseo preenchido por coágulo sanguíneo; grupo ultrassom terapêutico 10 minutos (GUS 10), com aplicação de ondas mecânicas emitidas pelo ultrassom terapêutico por 10 minutos sobre defeito ósseo preenchido por coágulo sanguíneo; grupo controle (GC), sem aplicação das ondas mecânicas emitidas pelo ultrassom terapêutico. Para aquisição das imagens macroscópicas, foi utilizada uma câmera digital Nikon D 3100 (Nikon Corp., Minato, Tóquio, Japão ).

\section{Protocolo de Aplicação do Ultrassom Terapêutico}

Os protocolos foram iniciados no $1^{\circ}$ dia do pós-operatório. Em todos os animais do GUS 5 e do GUS 10 foram realizadas anestesia e sedação para permitir a aplicação da terapêutica, seguidas de, quando necessário, tricotomia na região da calvária. Posteriormente, cada animal foi posicionado individualmente, em decúbito ventral, na mesa de procedimentos, e foi

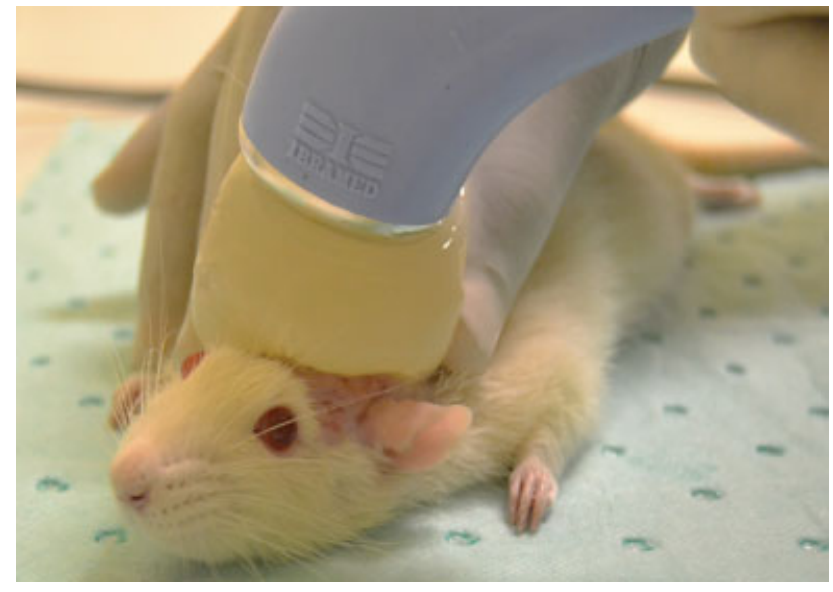

Fig. 2 Utilização do ultrassom terapêutico. Fonte: Elaboração da autora.

aplicado gel hidrossolúvel nas regiões da calvária e na parte superior da bolsa de água (-Figura 2).

Utilizou-se equipamento de ultrassom terapêutico de baixa intensidade, modelo Sonopulse III (Ibramed, Amparo, SP, Brasil), que havia sido previamente calibrado pelo fabricante, com frequência de $1 \mathrm{MHz}$, modo pulsado, intensidade $0,2 \mathrm{~W} / \mathrm{cm}^{2}$, $50 \%$ de ciclo de trabalho, frequência de repetição de pulso de $16 \mathrm{~Hz}$ e tamanho de área efetiva de radiação (AER) de $7 \mathrm{~cm}^{2}$. Durante a aplicação do ultrassom terapêutico, foram realizados movimentos lentos, circulares e contínuos com o transdutor, por 5 ou 10 minutos, a depender do grupo experimental. 0 protocolo foi realizado 5 vezes por semana, com pausa de 48 horas, nos pontos biológicos de 15, 30, e 60 dias, o que equivale, respectivamente, a 11, 22, e 44 aplicações do ultrassom.

Os protocolos foram estabelecidos após adaptação dos utilizados por Albertin, ${ }^{11}$ Barreto, ${ }^{17}$ e Skau et al., ${ }^{18}$ e realização de teste-piloto, por não se ter localizado, na literatura disponível, relato de protocolo de terapia por ultrassom terapêutico, com equipamento nacional, para regeneração de defeito ósseo
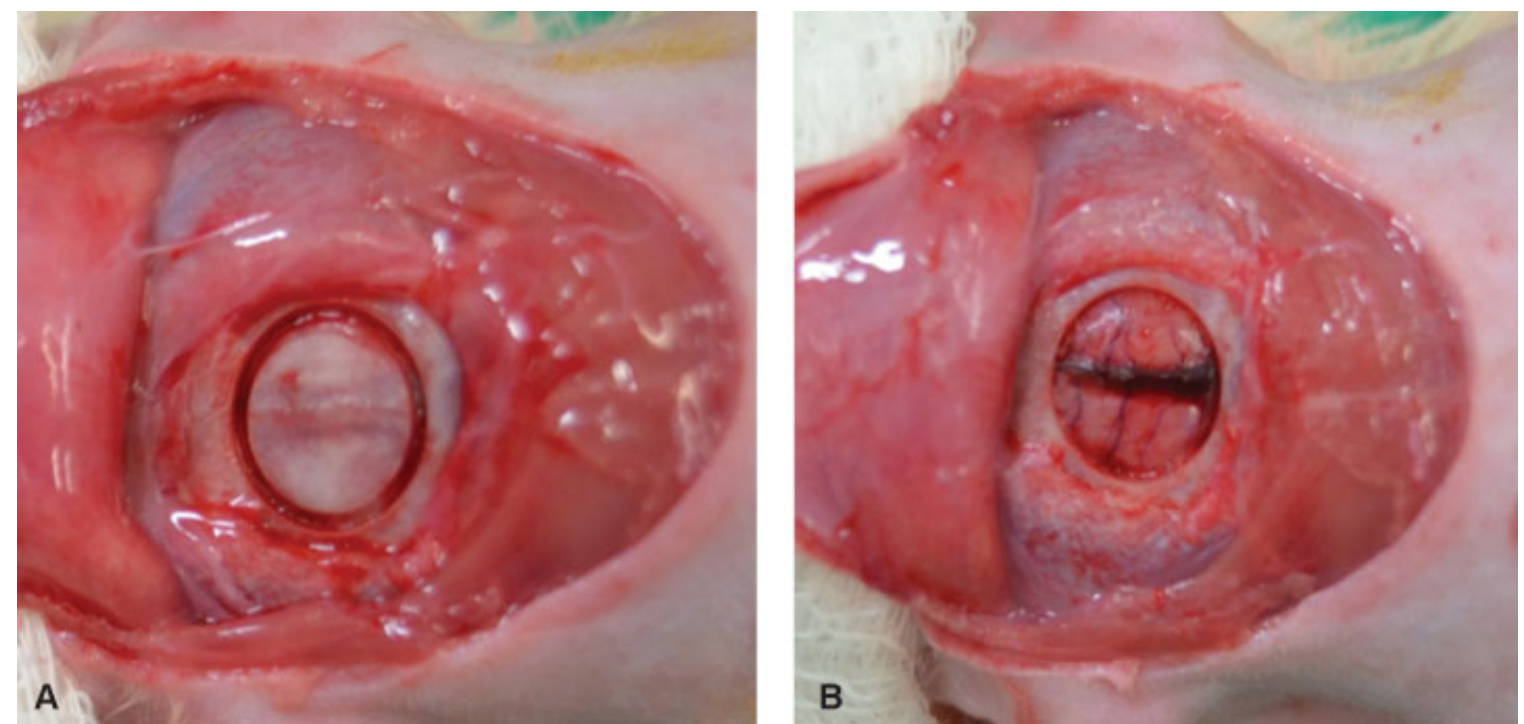

Fig. 1 Etapa do procedimento cirúrgico. Remoção do tecido subcutâneo, dos músculos e marcação do defeito (A); remoção do fragmento ósseo (B). Fonte: Elaboração da autora. 
crítico. Após os protocolos terapêuticos, os animais foram mantidos em local aquecido para recuperação da narcose anestésica e, em seguida, colocados em gaiolas individuais.

Após os pontos biológicos de 15, 30, e 60 dias, os animais foram eutanasiados, as calvárias foram removidas e fixadas em formol tamponado a $10 \%$ e mantidas em coletores plásticos por 72 horas. Em seguida, as amostras foram clivadas nas regiões laterais e inferior, seguindo-se a divisão em 2 porções, sendo de, aproximadamente, $2 / 3$ a anterior e de $1 / 3$ a posterior.

A porção anterior foi descalcificada em solução de ácido etileno-diamino-tetracético (EDTA) a 7\%, durante 7 dias, com troca do ácido a cada 24 horas. As calvárias foram processadas, incluídas em parafina e cortadas de forma seriada em um micrótomo com espessura de 5,0 $\mu \mathrm{m}$. Utilizou-se a técnica de coloração de rotina com hematoxilina e eosina (H\&E); para identificar proteínas colagênicas, empregou-se o picrosirius red (PIFG) e, para identificar a matriz óssea, foi usado o kit tricrômico de Masson-Goldner. Na análise histológica, foi utilizado o microscópio vertical digital Leica DM6 B (Leica Camera AG, Wetzlar, Alemanha) e o software LAS V4.12 (Leica Microsystems GmbH, Wetzlar, Alemanha).

\section{Resultados}

\section{Grupo ultrassom terapêutico 5}

Aos 15 dias, houve formação de matriz osteoide reacional e inespecífica (-Figura 3A), que foi incrementada aos 30 dias (-Figura 3B) e estabilizada aos 60 dias (-Figura 3C), embora restrita às regiões de borda óssea, com ausência do restabelecimento do volume ósseo original. Os osteoblastos ativos estavam presentes em todos os pontos biológicos. A extensão do defeito foi preenchida pela matriz de tecido conjuntivo frouxo, que apresentou menor espessura na região central do defeito aos 15 dias, evoluiu para o espessamento contínuo aos 30 dias, porém, aos 60 dias, sofreu redução (-Figura 3C). Em todos os pontos biológicos, notou-se a presença de fibras colágenas, que, aos 30 dias, apresentaram-se em paralelo (-Figura 3B), e proliferação difusa de capilares. Aos 15 dias o edema apresentava-se moderado, e havia presença de infiltrado inflamatório mononuclear difuso, que se reduziu aos 30 dias e tornou-se inconspícuo aos 60 dias.

\section{Grupo ultrassom terapêutico 10}

Aos 15 dias, a neoformação da matriz osteoide apresentava-se restrita à borda óssea ( - Figura 4A) e evoluiu, a partir dos 30 dias (-Figura 4B), para a formação em direção centrípeta (-Figura 4C), com ausência do restabelecimento do volume ósseo original. Os osteoblastos permaneceram presentes e ativos em todos os pontos biológicos, e o preenchimento da área do defeito ocorreu com tecido conjuntivo frouxo que apresentou aumento da espessura em toda a extensão. Em todos os pontos biológicos, as fibras colágenas estavam organizadas em paralelo ( - Figura 4B), houve proliferação de vasos sanguíneos, com estabilização da angiogênese aos 60 dias. 0 edema e o infiltrado inflamatório mononuclear apresentaramse reduzidos e tornaram-se ausentes aos 60 dias.

\section{Grupo controle}

A neoformação de matriz osteoide reacional apresentou-se restrita à borda óssea em todos os pontos biológicos ( - Figuras 5 A, B e C), e o volume ósseo original não foi reestabelecido. Apenas aos 15 dias, houve presença de osteoblastos ativos. 0
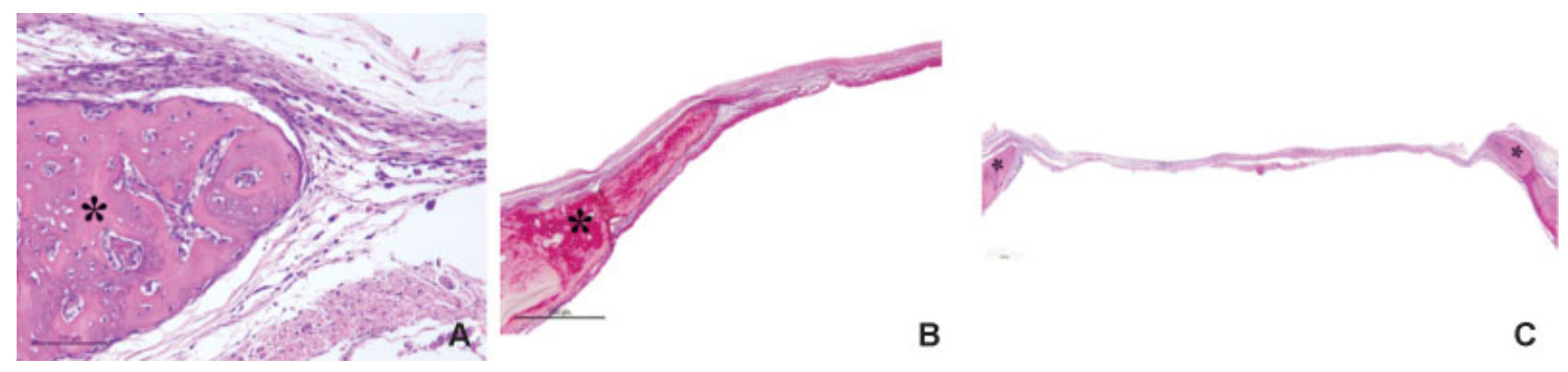

B

C

Fig. 3 Grupo ultrassom terapêutico 5 - Fotomicrografia do defeito ósseo crítico com presença de neoformação de matriz osteoide (*). (A) Aos 15 dias, presença de osteoblastos ativos e diversos espaços capilares (hematoxilina e eosina - H\&E). (B) Alinhamento das fibras colágenas aos 30 dias (PIFG). (C) Redução do espessamento do tecido conjuntivo frouxo aos 60 dias (H\&E). Fonte: Elaboração da autora.
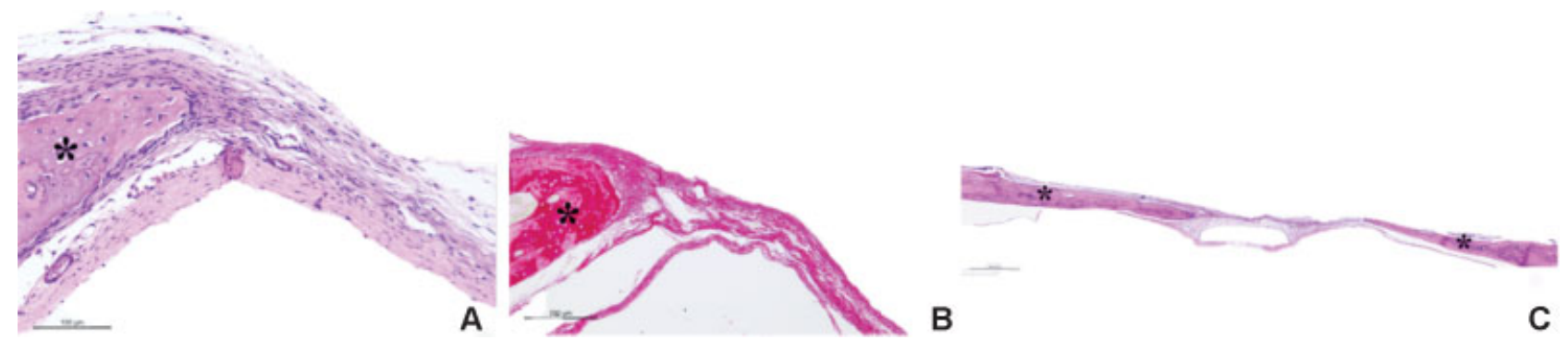

Fig. 4 Grupo ultrassom terapêutico 10 - Fotomicrografia da região do defeito ósseo crítico com presença de neoformação de matriz osteoide (*). (A) Presença de osteoblastos ativos e diversos espaços capilares aos 15 dias (hematoxilina e eosina - H\&E). (B) Organização das fibras colágenas em paralelo aos 30 dias (PIFG). (C) Neoformação de matriz osteoide em direção centrípeta aos 60 dias (H\&E). Fonte: Elaboração da autora. 

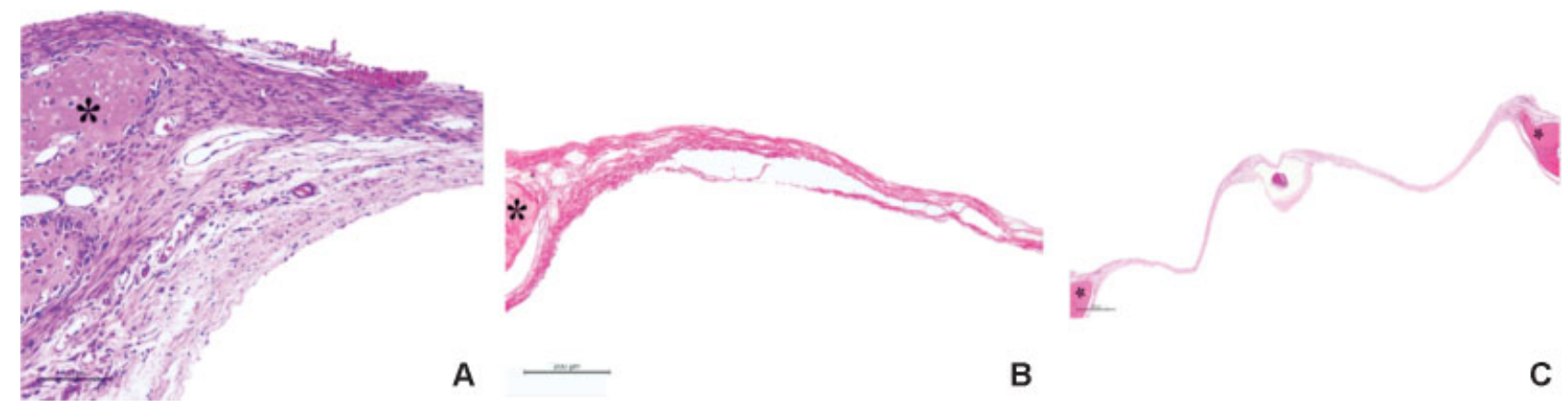

A

B

C

Fig. 5 Grupo controle - Fotomicrografia da região do defeito ósseo crítico com presença de neoformação de matriz osteoide $\left({ }^{*}\right)$. (A) Osteoblastos ativos e poucos espaços capilares aos 15 dias (hematoxilina e eosina - H\&E). (B) Preenchimento do defeito com delgado tecido conjuntivo frouxo aos 30 dias (PIFG). (C) Neoformação de matriz osteoide restrita às bordas ósseas aos 60 dias (H\&E). Fonte: Elaboração da autora.

preenchimento do defeito, em todos os pontos biológicos, ocorreu com tecido conjuntivo frouxo, que se apresentou delgado aos 15 dias e ainda mais delgado aos 60 dias (-Figura 5C), com espessura menor que a borda óssea. Constataram-se poucos capilares e, aos 30 e 60 dias, estabilização da angiogênese, discreto edema e infiltrado inflamatório mononuclear difuso que se tornaram ausentes posteriormente.

\section{Discussão}

A ausência da padronização de protocolos de ultrassom terapêutico com a finalidade de auxiliar a regeneração tecidual pode comprometer o resultado terapêutico desejado. Desse modo, é necessário que sejam eleitos com cautela e que se unifiquem os parâmetros a serem utilizados na reabilitação. ${ }^{8}$ Dentre os diversos parâmetros está a variável tempo, pouco estudada nos artigos científicos disponíveis, impondo-se, portanto, a necessidade de definir o tempo de tratamento a ser empregado em cada lesão. ${ }^{8}$ Sendo assim, o presente experimento buscou comparar o efeito de dois protocolos de diferentes tempos de tratamento do ultrassom terapêutico na regeneração de defeito ósseo crítico.

A realização da terapia com ondas ultrassônicas na fase inicial incrementou o reparo tecidual, pois o efeito do ultrassom está relacionado, principalmente, com o intervalo de tempo entre o início da lesão e o início do tratamento, de modo que, quanto mais precocemente se iniciar a terapia, mais rápida será a recuperação tecidual. 2,19-21

No presente estudo, os resultados obtidos na fase inicial do reparo mostraram que os tempos de 5 e 10 minutos não foram suficientes para estimular o aumento da neoformação no defeito ósseo crítico. ${ }^{10} \mathrm{~A}$ evolução apresentada nos demais pontos biológicos do GUS 5 pode ter sido motivada pelo prolongamento do estímulo no tecido ósseo, que é capaz de promover regiões de remodelação, ${ }^{10}$ sendo considerado um tempo suficiente para promover a consolidação óssea. ${ }^{18}$ Entretanto, alguns autores ${ }^{11,22,23}$ afirmam que o tempo ideal para promover o estímulo osteogênico e a organização tecidual é a partir de 10 minutos, o que sugere que o ultrassom possui efeito dose-dependente quanto ao tempo de estimulação.

$\mathrm{O}$ incremento constatado nos pontos biológicos tardios do GUS 10 pode ter ocorrido em consequência do prolongamento do estímulo na via de mecanotransdução, que potencializa o estímulo osteogênico e gera aumento da taxa de neoformação óssea. ${ }^{24}$ Entretanto, no GC houve manutenção da limitação da neoformação ${ }^{24}$ em razão da ausência de estímulo adicional.

0 padrão celular encontrado nos grupos experimentais em que se realizou a terapia com ultrassom demonstrou que as ondas ultrassônicas são capazes de induzir e fomentar a ativação e a diferenciação de células mesenquimais e osteoprogenitoras. ${ }^{19,24}$ Apesar de não estar elucidado esse mecanismo de indução à osteogênese por meio desse recurso terapêutico, ${ }^{24}$ sabe-se que o ultrassom estimula as células mesenquimais a se diferenciar em osteoblastos, que, por sua vez, têm sua atividade celular estimulada. Além disso, o ultrassom acelera a diferenciação dos osteoblastos e promove aumento da mineralização óssea. ${ }^{25,26}$

O tecido de reparo que preencheu o defeito no GUS 5 e no GUS 10 foi estimulado pelas ondas ultrassônicas que, além de fomentar a síntese de células mesenquimais, estimulam colágeno e fibroblastos, principalmente quando utilizadas na fase inicial do reparo, ${ }^{10,19,20,24}$ como se procedeu neste experimento. A partir de 2 minutos de emissão das ondas ultrassônicas, ocorre o estímulo ao crescimento de fibroblastos $^{27}$ e o alinhamento das fibras de colágeno acontece a partir de 3 minutos. ${ }^{8}$

Neste estudo, o ultrassom mostrou-se promissor no estímulo à angiogênese tanto aos 5 quanto aos 10 minutos de terapia, quando ocorre a vascularização a partir da fase inicial do reparo ${ }^{10}$ e torna-se evidente na fase tardia, o que favorece o processo de reparo ósseo. ${ }^{25}$

Há duas hipóteses para justificar a angiogênese promovida pelo ultrassom: o estímulo ao aumento da secreção de interleucina-8 (IL-8) e a produção do fator de crescimento endotelial vascular (FCEV). Supõe-se que as ondas ultrassônicas regulam a secreção da IL-8 pelos osteoblastos, por ser uma citocina responsável por induzir a proliferação e a migração de células endoteliais, o que leva à angiogênese. A segunda hipótese sugere que o ultrassom estimula a produção de FCEV também pelos osteoblastos, um fator fundamental para a angiogênese, que atua na regulação da mitose e no recrutamento das células endoteliais. ${ }^{28}$

As ondas ultrassônicas promoveram a redução do tempo do processo inflamatório após os tempos de 5 e 10 minutos 
de terapia, por favorecer a aceleração da fase inflamatória, decorrente do aumento e da liberação de células mononucleares, assim como da liberação de histaminas, que fomenta uma rápida resolução do processo inflamatório. ${ }^{20,29}$ Devido a esse mecanismo, o ultrassom é capaz de eliminar o processo inflamatório a partir da fase inicial do reparo. ${ }^{23}$

O ultrassom terapêutico, apesar de apresentar efeito osteogênico e possibilitar seu uso em situações em que o reparo é crítico, não mostrou eficácia quanto ao restabelecimento do volume e da morfologia do tecido ósseo original em ambos os protocolos. Dessa forma, a fim de potencializar os efeitos das ondas ultrassônicas, sugere-se uma possível associação desse recurso terapêutico a um arcabouço tridimensional, que servirá de maior suporte estrutural e mecânico, potencializará o crescimento celular e induzirá a diferenciação celular. ${ }^{16,30}$

\section{Conclusão}

O ultrassom terapêutico estimulou o reparo do defeito ósseo crítico, e o tempo mais longo de exposição promoveu maior estímulo osteogênico.

Conflito de Interesses

Os autores declaram não haver conflito de interesses.

\section{Agradecimentos}

Os autores agradecem à Coordenação de Aperfeiçoamento de Pessoal de Nível Superior (CAPES) pelo suporte dado a este trabalho.

\section{Referências}

1 Andia DC, Cerri PS, Spolidorio LC. Tecido ósseo: aspectos morfológicos e histofisiológicos. Rev Odontol UNESP 2006;35(02):191-198

2 Pereira AJ, Amorim M, Catelani F, et al. The influence of lowintensity physioterapeutic ultrasound on the initial stage of bone healing in rats: an experimental and simulation study. J Ther Ultrasound 2016;4(24):1-8

3 Logeart-Avramoglou D, Anagnostou F, Bizios R, Petite H. Engineering bone: challenges and obstacles. J Cell Mol Med 2005;9(01):72-84

4 Almeida RS, Ribeiro II, Silva MH, Rocha DN, Miguel FB, Rosa FP. Avaliação da fase inicial do reparo ósseo após a implantação de biomateriais. Rev Ciênc Méd Biol 2014;13(03):331-336

5 Colnot C. Skeletal cell fate decisions within periosteum and bone marrow during bone regeneration. J Bone Miner Res 2009;24(02): 274-282

6 Lirani APR, Lazaretti-Castro M. Evidências da ação de agentes físicos sobre o metabolismo do tecido ósseo e seus potenciais usos clínicos. Arq Bras Endocrinol Metabol 2005;49(06):891-896

7 Király M, Varga Z, Szanyó F, Kiss R, Hodosi K, Bender T. Effects of underwater ultrasound therapy on pain, inflammation, hand function and quality of life in patients with rheumatoid arthritis - a randomized controlled trial. Braz J Phys Ther 2017;21(03):199-205

8 Farcic TS, Lima RM, Machado AF, et al. Aplicação do ultrassom terapêutico no reparo tecidual do sistema musculoesquelético. Arq Bras Ciênc Saúde. 2013;37(03):149-153

9 Apolinario JC, Coleho WM, Louzada MJ. Análise da influência do ultrassom de baixa intensidade na região de reparo ósseo em ratos sob ausência de carga. Fisioter Pesqui 2011;18(03):257-259

10 Fávaro-Pípi E, Feitosa SM, Ribeiro DA, et al. Comparative study of the effects of low-intensity pulsed ultrasound and low-level laser therapy on bone defects in tibias of rats. Lasers Med Sci 2010;25 (05):727-732
11 Albertin LM. Efeito do ultra-som sobre o reparo de falha óssea experimental: avaliação quantitativa e morfológica do parâmetro tempo de estimulação. Rev Bras Fisioter. 2004;8(01):1-6

12 Azuma Y, Ito M, Harada Y, Takagi H, Ohta T, Jingushi S. Lowintensity pulsed ultrasound accelerates rat femoral fracture healing by acting on the various cellular reactions in the fracture callus. J Bone Miner Res 2001;16(04):671-680

13 Miguel FB, Barbosa Júnior AdeA, de Paula FL, Barreto IC, Goissis G, Rosa FP. Regeneration of critical bone defects with anionic collagen matrix as scaffolds. J Mater Sci Mater Med 2013;24(11):2567-2575

14 Câmara-Pereira ES, Rolim AEH, Reale R, et al. Analysis of bone repair tissue after implantation of biomaterials and application of vibratory waves. Mater Sci Forum 2014;775-776:9-12

15 Ribeiro II, Almeida RS, Rocha DN, Silva MH, Miguel FB, Rosa FP. Biocerâmicas e polímero para a regeneração de defeitos ósseos críticos. Rev Ciênc Méd Biol 2014;13(03):2298-2302

16 Daltro AF, Barreto IC, Rosa FP. Análise do efeito da plataforma vibratória na regeneração de defeito ósseo crítico. Rev Ciênc Méd Biol 2016;15(03):323-329

17 Barreto AA. Efeito do ultrassom terapêutico sobre o crescimento ósseo das epífises, distal do fêmur e proximal da tibia em rattus norvegicus. [tese]. Botucatu: Faculdade de Medicina de Botucatu, Universidade Estadual Júlio de Mesquita Filho; 2009

18 Skau JR, Rodrigues B, Rosa FO, Araujo RC, Fontinele RG, Souza RR. Histomorphometrical analysis on the effects of two therapeutic ultrasound intensities on fracture healing in aged rats. Fisioter Mov 2014;27(02):173-179

19 Acar AH, Yolcu Ü, Altındiş S, Gül M, Alan H, Malkoç S. Bone regeneration by low-level laser therapy and low-intensity pulsed ultrasound therapy in the rabbit calvarium. Arch Oral Biol 2016; 61(01):60-65

20 Silva JM, Carvalho JP, Moura-Junior MJ, et al. Estudo da ação do ultrassom terapêutico em modelo experimental de tendinite em ratos Wistar. Com Sci Saude 2010;9(04):625-632

21 Pereira AJ, Teixeira RC, Oliveira AJ, Pontes RW, Barros RS, Negrão JN. Efeito do ultrassom terapêutico de baixa intensidade em fratura induzida em tibia de ratos. Acta Ortop Bras 2013;21(01):18-22

22 Silveira DS, Pippi NL, Costa FS, et al. O ultra-som terapêutico de $1 \mathrm{MHz}$, na dose de $0,5 \mathrm{Wcm}^{2}$, sobre o tecido ósseo de cães avaliado por densitometria óptica em imagens radiográficas. Cienc Rural 2008;38(08):2225-2231

23 Oliveira P, Sperandio E, Fernandes KR, Pastor FAC, Nonaka KO, Renno ACM. Comparação dos efeitos do laser de baixa potência e do ultrassom de baixa intensidade no processo de reparo ósseo em tibia de rato. Rev Bras Fisioter 2011;15(03):200-205

24 Jung YJ, Kim R, Ham HJ, et al. Focused low-intensity pulsed ultrasound enhances bone regeneration in rat calvarial bone defect through enhancement of cell proliferation. Ultrasound Med Biol 2015;41(04):999-1007

25 Zhu H, Cai X, Lin T, Shi Z, Yan S. Low-intensity pulsed ultrasound enhances bone repair in a rabbit model of steroid-associated osteonecrosis. Clin Orthop Relat Res 2015;473(05):1830-1839

26 Macione J, Long D, Nesbitt S, et al. Stimulation of osteoblast differentiation with guided ultrasound waves. J Ther Ultrasound 2015;3(12):12

27 Oliveira PD, Oliveira DA, Martinago CC, Frederico RC, Soares CP, Oliveira RF. Efeito da terapia ultrassônica de baixa intensidade em cultura celular de fibroblastos. Fisioter Pesqui 2015;22(02): 112-118

28 Padilla F, Puts R, Vico L, Raum K. Stimulation of bone repair with ultrasound: a review of the possible mechanic effects. Ultrasonics 2014;54(05):1125-1145

29 Pereira T, Ferreira BS, Alves WS, Filho AL. Ação do ultrassom terapêutico e laser de baixa intensidade na regeneração nervosa em rattus norvegicus. Con Sci Saude. 2014;13(01):22-30

30 Akilal N, Lemaire F, Bercu NB, et al. Cowries derived aragonite as raw biomaterials for bone regenerative medicine. Mater Sci Eng $C$ 2019;94(01):894-900 